\title{
Outcome of Pediatric Traumatic Cataract in Upper Egypt: A Tertiary Center Study
}

This article was published in the following Dove Press journal: Clinical Ophthalmology

\author{
Salma M Kedwany (iD \\ Mohamed GA Saleh (D) \\ Dalia Tohamy (ID \\ Magdi M Mostafa (ID
}

Department of Ophthalmology, Faculty of Medicine, Assiut University, Assiut, Egypt

Correspondence: Magdi M Mostafa Department of Ophthalmology, Assiut University, Assiut, 71515, Egypt

Tel +201093 I 22344

Email magdimohammad2013@gmail.com
Purpose: To demonstrate the demographic features, causative agents, and outcome of pediatric traumatic cataract surgery in eyes without posterior segment involvement at Assiut University Hospital, Upper Egypt.

Patients and Methods: This is a retrospective study on children (aged $<18$ years old) who underwent traumatic cataract surgery from January to June 2019. Children with posterior segment injury and those who did not complete 6 months of postoperative follow-up were excluded. The demographic features, mechanism and time of eye injury, clinical features, surgical approach, and outcome were recorded and analyzed.

Results: The study included 34 eyes of 34 children, 23 (68\%) of them were boys. The mean age at the time of cataract surgery was $10 \pm 3.97$ years. Twenty-one eyes sustained open globe injury $(62 \%)$ with the most common cause of trauma was wooden sticks, while 13 eyes had closed globe injury (38\%) with the most common cause of injury was thrown stones. The time interval between eye injury and cataract surgery ranged from 1 day to 9 years with a median of 2.05 months. Posterior chamber intraocular lenses were implanted in all eyes; in 33 eyes, the posterior chamber intraocular lenses were implanted primarily at the time of cataract extraction. Corrected distance visual acuity significantly improved from $2.63 \pm 0.66$ LogMAR preoperatively, to $0.41 \pm 0.38$ LogMAR postoperatively $(\mathrm{p}<0.001)$.

Conclusion: Pediatric traumatic cataract is commonly present in primary school age especially after open globe injury. Primary prevention through health awareness should target this age population. Useful vision can be regained with timely proper surgical intervention and posterior chamber intraocular lens implantation.

Clinicaltrials.gov Id: NCT04630509.

Keywords: pediatric cataract, pediatric ocular trauma, lens, posterior chamber intraocular lenses implantation

\section{Introduction}

Ocular trauma is one of the leading causes of acquired unilateral blindness in childhood. $^{1,2}$ Apart from the permanent disability, ocular trauma has a profound impact on both patients and society at different levels, including, but not limited to, psychological trauma, cosmetic disfigurement, socioeconomic costs, and the need for specialized medical care and vocational rehabilitation. ${ }^{3-5}$

Traumatic cataract is a common complication of pediatric eye injury. In developing countries, ocular trauma was responsible for up to $45 \%$ of childhood cataract. $^{6-10}$ Traumatic cataract was present in 33\% of children with an eye injury admitted to the hospital in Upper Egypt. ${ }^{11}$ Vision loss induced by traumatic cataract is surgically manageable. However, the high risk of postoperative inflammation, 
posterior capsular opacification (PCO), amblyopia, and the associated ocular tissue damage including corneal opacification may negatively impact the visual outcome. Furthermore, difficult intraocular lens power calculation in these growing eyes with altered anterior chamber depth especially with open globe injuries (OGIs) adds more challenge to the outcome of traumatic cataract surgery in children.

Several studies reported visual outcome of pediatric traumatic cataract in different populations. ${ }^{12-15}$ With the scarcity of studies on traumatic cataract in Egyptian children, we conducted this retrospective study to report the demographic features, visual outcome, and complications of pediatric traumatic cataract at Assiut University Hospital, the biggest tertiary referral center in Upper Egypt.

\section{Patients and Methods}

The study was approved by the Institutional Review Board of Assiut University and adhered to the tenets of the Declaration of Helsinki. A detailed written parental permission was obtained from the parents or the guardians of all children. Oral and signed assents were obtained from children aged more than 7 years whenever possible.

The medical records of children (aged $<18$ years old) admitted for traumatic cataract surgery at the department of ophthalmology; Assiut University Hospital, in the period between January and June 2019, were retrospectively reviewed. Exclusion criteria included a follow-up period less than 6 months, posterior segment injury (eg, retinal detachment, vitreous hemorrhage, or retained intraocular foreign bodies), and pre-existing ocular disease.

The following data were collected and analyzed: patient's demographics, ocular trauma details, time interval between trauma and cataract surgery, preoperative ocular examination findings, operative data, complications, and corrected distance visual acuity (CDVA) at the final follow-up visit, with the conversion of Snellen acuity to the LogMAR equivalent for accurate statistical analysis. ${ }^{16}$ Eye injury was classified according to "The Birmingham Eye Trauma Terminology system" into open globe injury (OGI) and closed globe injury (CGI). ${ }^{17}$ Zones of OGI were recorded according to "The Ocular Trauma Classification". ${ }^{18}$

Cataract was extracted with either standard irrigation/ aspiration of the lens matter using the bimanual technique or lensectomy using the vitrector. Primary posterior capsulotomy and anterior vitrectomy were performed for children aged less than 8 years with an intact posterior capsule. Cataract surgery was performed as a second intervention after timely wound repair of OGI as needed.

Postoperative prednisolone acetate $1 \%$ eye drops eight times/day, cyclopentolate hydrochloride $1 \%$ eye drops three times/day, and moxifloxacin hydrochloride $0.5 \%$ eye drops five times/day, were prescribed for 2 weeks. Topical steroids were tapered over 6 weeks according to the inflammatory response. Systemic steroids $1 \mathrm{mg} / \mathrm{Kg}$ oral prednisone was prescribed in resistant cases and tapered over 4 weeks.

Data entry and analysis were done using IBM SPSS (statistical package for social science) Statistics for Windows, Version 20.0. Armonk, NY: IBM Corp. Descriptive statistics were used to calculate mean, standard deviations (SDs), median, and range for continuous variables. For categorical variables, percentages were calculated. Test of normality was done using Shapiro-Wilks analysis. The Wilcoxon signed-rank test was used to compare between pre- and final CDVA. The independent samples Mann-Whitney $U$-test was used to compare CDVA between OGI and CGI groups. A p-value $<0.05$ was considered statistically significant.

\section{Results}

\section{Demographics}

Thirty-four eyes of 34 children were included in this study with a mean follow-up period of $7.3 \pm 1.7 \mathrm{SD}$ months (range, 6 months -12 months). The mean age at the time of cataract surgery was $10 \pm 3.97$ years (range, 3 years -17 years). Half of the children were between 6-11 years old (primary school age) as shown in Table 1 . There were 23 boys $(68 \%)$ and 11 girls (32\%); the overall male to female ratio was $2.1: 1$ ( $\mathrm{p}=0.058$, binominal test). Eye injury was unilateral in all cases; the right eye was involved in 19 children, and the left eye was involved in 15 children.

\section{Eye Injury Details}

Associated OGI was present in 21 eyes (62\%) and CGI was present in 13 eyes (38\%). All OGIs were of the penetrating

Table I Age Distribution of the Patients

\begin{tabular}{|l|l|l|}
\hline Age Groups in Years & No. & (\%) \\
\hline Preschool (0-5) & 5 & $(14.7 \%)$ \\
Primary school (6-II) & 17 & $(50 \%)$ \\
Secondary school (12-17) & 12 & $(35.3 \%)$ \\
\hline
\end{tabular}


type and involved zone I. Wooden sticks were the most common cause of OGI, while thrown stones were the most common cause of CGI. The causative agent was unknown in 4 cases. Table 2 shows the different causes of eye injury.

The time interval between injury and cataract surgery ranged from 1 day to 9 years, with a median of 2.05 months. In OGIs, it ranged from 1 month to 9 years with a median of 2.1 months, while in CGIs, it ranged from 1 day to 1 year with a median of 1.73 months.

\section{Associated Ocular Injuries}

A full-thickness corneal laceration was present in all eyes of OGI (21 eyes). Primary surgical repair was required in 16 eyes (76.2\%). Four eyes (19\%) had a small self-sealed wound and required only a bandage contact lens. One eye (4.8\%) had an old neglected unrepaired corneal wound that healed spontaneously with a dense corneal scar and anterior synechiae.

At the time of cataract surgery, corneal scarring and iris synechiae were the most common associated findings in OGIs $(76.2 \%)$, while pupillary sphincter rupture was the most frequent finding in CGIs (23\%), as shown in Table 3.

Regarding the type of cataract, there was a total cataract in 26 eyes, a posterior subcapsular with sectoral cortical cataract in 4 eyes, a cortical cataract in 3 eyes, and a membranous cataract in 1 eye.

\section{Surgical Outcome}

Standard irrigation/aspiration of lens matter was performed in all cases except one eye with membranous cataract,

Table 2 The Causative Agents of Eye Injury

\begin{tabular}{|l|l|l|l|l|}
\hline Causative Agent & $\begin{array}{l}\text { Open } \\
\text { Globe } \\
\text { Injury }\end{array}$ & $\begin{array}{l}\text { Closed } \\
\text { Globe } \\
\text { Injury }\end{array}$ & Total & Percent \\
\hline Wooden stick & 8 & 0 & 8 & $23.5 \%$ \\
Stone & 2 & 4 & 6 & $17.6 \%$ \\
Toy & 2 & 2 & 4 & $11.8 \%$ \\
Glass & 2 & 0 & 2 & $5.9 \%$ \\
Knife & 2 & 0 & 2 & $5.9 \%$ \\
Balloon & 1 & 1 & 2 & $5.9 \%$ \\
Scissor & 1 & 0 & 1 & $2.9 \%$ \\
Cap of exploded & 1 & 0 & 1 & $2.9 \%$ \\
carbonated drink bottle & & & 1 & \\
Fall from height & 0 & 1 & 1 & $2.9 \%$ \\
Whip & 0 & 1 & 1 & $2.9 \%$ \\
Football & 0 & 2 & $2.9 \%$ \\
Plastic pellet of airsoft gun & 0 & 2 & 13 & $100 \%$ \\
Unknown & 21 & $1.8 \%$ \\
Total & & 1 & & \\
\hline
\end{tabular}

Table 3 The Associated Ocular Findings

\begin{tabular}{|l|l|l|l|}
\hline Associated Ocular Finding & $\begin{array}{l}\text { Open } \\
\text { Globe } \\
\text { Injury }\end{array}$ & $\begin{array}{l}\text { Closed } \\
\text { Globe } \\
\text { Injury }\end{array}$ & Total \\
\hline Corneal scarring (Peripheral/Central) & $16(8 / 8)$ & 0 & 16 \\
Iris synechiae & 16 & 0 & 16 \\
Iris tissue defect/damage & 4 & 0 & 4 \\
Pupillary sphincter rupture & 0 & 3 & 3 \\
Ruptured anterior capsule with escaped lens matter & 3 & 1 & 4 \\
Fibrotic anterior capsule & 13 & 1 & 14 \\
Zonular dehiscence & 0 & 2 & 2 \\
Ruptured posterior capsule & 10 & 0 & 10 \\
\hline
\end{tabular}

thickened and fibrosed anterior lens capsule with subcapsular fibrous plaques, and sheet-like cortex which required lensectomy using the vitrector and micro-scissors.

Anterior vitrectomy was required in 10 eyes of OGI with ruptured posterior capsule and vitreous loss. Elective primary posterior capsulotomy with anterior vitrectomy was performed in 8 eyes ( 7 eyes had OGI, and 1 eye had CGI).

Primary posterior chamber intraocular lenses (PCIOL) implantation was performed in 33 eyes (97.1\%), while secondary PCIOL implantation was performed in one eye (2.9\%) after 1.5 months. A foldable one-piece hydrophobic acrylic IOL was implanted in the bag in 23 eyes (67.6\%), a foldable acrylic multi-piece PCIOL was implanted in the sulcus in 7 eyes $(20.6 \%)$, and a hard polymethyl methacrylate (PMMA) PCIOL was implanted in the sulcus in 4 eyes $(11.8 \%)$.

\section{Complications}

Two eyes developed optic capture of foldable hydrophobic acrylic IOLs; one eye of them required synchieolysis and IOL reposition. Significant visual axis obscuration due to PCO was observed in 5 eyes, for which YAG posterior capsulotomy was done in 4 eyes, while membranectomy and surgical capsulotomy were required in 1 eye. Significant postoperative anterior uveitis developed in 2 eyes. Amblyopia developed in 2 children. None of the cases developed secondary glaucoma or posterior segment complications.

\section{Visual Acuity}

About 91\% of children (31/34) cooperated in the assessment of CDVA. The mean preoperative CDVA was $2.63 \pm 0.66$ in $\log$ MAR. There was no significant difference in the mean preoperative logMAR CDVA between the OGI group (2.68, $\mathrm{n}=20$ ) and the CGI group $(2.55, \mathrm{n}=11), \mathrm{P}=0.53$, MannWhitney $U$-test. A preoperative CDVA of hand motion with 
good light projection (HMGP) was present in $76.2 \%$ (16 eyes) of the OGI group and $53.8 \%$ ( 7 eyes) of the CGI group. The distribution of the preoperative CDVA in OGI and CGI groups is shown in Table 4.

The postoperative CDVA was improved in 30 out of 31 eyes (96.8\%). About $41.9 \%$ of children achieved a CDVA of $6 / 9$ or better at the final follow-up visit. The distribution of the CDVA at the final visit is shown in Table 5.

The mean CDVA at the final visit was $0.41 \pm 0.38$ in $\operatorname{logMAR}$ ( $\mathrm{n}=31$ eyes), which was significantly better than the preoperative value $(\mathrm{p}<0.001$, Wilcoxon signed-rank test). Each of the OGI and CGI groups showed significant improvement of the CDVA ( $p<0.001$ and $p=0.003$, respectively, Wilcoxon signed-rank test), as shown in Table 6. The final CDVA was significantly better in the CGI group than in the OGI group $(\mathrm{p}=0.01$, MannWhitney $U$-test). Eyes with IOLs in the bag had a better logMAR CDVA (0.34) than those with IOLs in the sulcus (0.55), $(\mathrm{p}=0.048$, Mann-Whitney $U$-test). In the OGI group, the mean CDVA in $\log$ MAR was significantly worse in eyes with a central corneal laceration $(0.72)$

Table 4 The Distribution of Preoperative CDVA

\begin{tabular}{|c|c|c|c|c|c|c|}
\hline \multirow[t]{2}{*}{ CDVA } & \multicolumn{2}{|c|}{$\begin{array}{c}\text { Open Globe } \\
\text { Injury }\end{array}$} & \multicolumn{2}{|c|}{$\begin{array}{l}\text { Closed Globe } \\
\text { Injury }\end{array}$} & \multicolumn{2}{|c|}{ Total } \\
\hline & No. & $\%$ & No. & $\%$ & No. & $\%$ \\
\hline$\geq 6 / 60$ & 2 & 9.5 & 0 & 0 & 2 & 5.9 \\
\hline$<6 / 60$ to $>$ HMGP & 2 & 9.5 & 4 & 30.8 & 6 & 17.6 \\
\hline HMGP & 16 & 76.2 & 7 & 53.8 & 23 & 67.6 \\
\hline Cannot be assessed & 1 & 4.8 & 2 & 15.4 & 3 & 8.8 \\
\hline Total & \multicolumn{2}{|c|}{21} & \multicolumn{2}{|c|}{13} & \multicolumn{2}{|c|}{34} \\
\hline
\end{tabular}

Abbreviations: CDVA, corrected distance visual acuity; HMGP, hand motion with a good projection of light.

Table 5 The Distribution of Postoperative CDVA

\begin{tabular}{|c|c|c|c|c|c|c|}
\hline \multirow[t]{2}{*}{ CDVA } & \multicolumn{2}{|c|}{$\begin{array}{c}\text { Open Globe } \\
\text { Injury }\end{array}$} & \multicolumn{2}{|c|}{$\begin{array}{l}\text { Closed Globe } \\
\text { Injury }\end{array}$} & \multicolumn{2}{|c|}{ Total } \\
\hline & No. & $\%$ & No. & $\%$ & No. & $\%$ \\
\hline$\geq 6 / 9$ & $5 / 20$ & 25 & $8 / 11$ & 72.7 & $|3 / 3|$ & 41.9 \\
\hline$<6 / 9$ to $6 / 18$ & $7 / 20$ & 35 & $3 / 11$ & 27.3 & $|0 / 3|$ & 32.3 \\
\hline$<6 / 18$ to $6 / 36$ & $5 / 20$ & 25 & $0 / 11$ & 0 & $5 / 31$ & 16.1 \\
\hline $6 / 60$ & $2 / 20$ & 10 & $0 / 11$ & 0 & $2 / 31$ & 6.5 \\
\hline$<6 / 60$ & $1 / 20$ & 5 & $0 / 11$ & 0 & $0 / 31$ & 0 \\
\hline $\begin{array}{l}\text { Cannot be } \\
\text { assessed }\end{array}$ & $\mid / 21$ & 4.8 & $2 / 13$ & 15.4 & $3 / 34$ & 8.8 \\
\hline Total & \multicolumn{2}{|c|}{21} & \multicolumn{2}{|c|}{13} & \multicolumn{2}{|c|}{34} \\
\hline
\end{tabular}

Table 6 The Mean Preoperative and Final LogMAR CDVA in Both Groups

\begin{tabular}{|l|l|l|l|l|}
\hline $\begin{array}{l}\text { CDVA in } \\
\text { LogMAR }\end{array}$ & Total & $\begin{array}{l}\text { Open Globe } \\
\text { Injury }\end{array}$ & $\begin{array}{l}\text { Closed Globe } \\
\text { Injury }\end{array}$ & p-value $^{\mathbf{a}}$ \\
\hline Preoperative & 2.63 & 2.68 & 2.55 & 0.53 \\
Postoperative & 0.41 & 0.52 & 0.21 & 0.01 \\
p-value $^{\mathrm{b}}$ & $<0.001$ & $<0.001$ & 0.003 & \\
\hline
\end{tabular}

Notes: ${ }^{a} \mathrm{p}$-value of difference between open and closed globe injury groups; $\mathrm{b}$-value of difference between pre- and post-operative visits within the same group. Abbreviation: CDVA, corrected distance visual acuity.

than with a peripheral corneal laceration (0.39), $(\mathrm{p}=0.007$, Mann-Whitney $U$-test). The postoperative CDVA did not improve in only one 14-year-old child due to the long-time interval between the globe injury and cataract surgery ( 9 years) with resultant deep amblyopia. The age, gender, and time interval between injury and cataract surgery had no statistically significant impact on the final CDVA.

\section{Discussion}

This retrospective study included 34 children presented with traumatic cataract, which was more commonly associated with open globe injury. Wooden sticks followed by thrown stones were the most common causes of injury. Significant visual improvement was obtained with timely surgical intervention and IOL implantation.

The risk of a severe postoperative inflammatory response in actively developing pediatric eyes, and amblyopia requiring long visual rehabilitation are major factors that make the outcome of cataract surgery more challenging in children than that in adults. ${ }^{19}$ Furthermore, the coexistent damage inflicted by the trauma makes the outcome of traumatic cataract less favorable. Fortunately, most children sustain traumas after the first year of life (after the development of fixation reflexes), decreasing the risk of deep amblyopia. ${ }^{20}$

In this series, the incidence of traumatic cataract was higher in boys than in girls (the overall ratio was 2.1:1) which could be attributed to the aggressive behavior and greater involvement of boys in outdoor and sports activities. A similar finding was reported in multiple previous studies. ${ }^{15,21,22}$

Half of the children were in primary school age; when children become more independent and commonly participate in outdoor activities without adequate guardian supervision. This age incidence was similar to studies from India ${ }^{15}$ and Guatemala, ${ }^{23}$ while most cases in studies from China ${ }^{22}$ and USA $^{12}$ were in preschool age. This, on 
the one hand, reflects that different social, cultural, and economic factors may influence the children's activities in different areas of the world; and on the other hand, may reflect the lack of organized safety education programs that should be received at school in the developing countries. Moreover, the relatively older age of children in our study (10 \pm 3.97 years) can explain the better cooperation in the testing of pre- and postoperative visual acuities; $91.2 \%$ cooperated, when compared to the study reported by $\mathrm{Du}$ et $\mathrm{al},{ }^{22}$ that had a relatively younger age $(6.3 \pm 3.7$ years) where only $71 \%$ of children cooperated during visual acuity testing.

Associated OGIs were more common in our series, similar to other studies from different parts of the world. $^{24,25}$ This may reflect the nature of OGIs, which is commonly associated with other ocular structural damage, and so the risk of traumatic cataract is more common.

Different causative agents of pediatric traumatic cataract were reported. ${ }^{26}$ Wooden sticks were the most common cause of traumatic cataract in this study, followed by stones, toys, and then other household tools as scissors and knives. Similarly, a previous study in our hospital reported that wooden sticks and stones are the most common agents involved in pediatric ocular injuries. ${ }^{11}$ Multiple studies from other developing countries reported the same finding. ${ }^{13,24,27}$ The high prevalence of wooden stick injuries in Upper Egypt is attributed to the fact that the main occupation of the inhabitants is agriculture, and some children may participate in agricultural work.

The final CDVA could be measured in 31 children, $74 \%$ of them achieved CDVA of $6 / 18$ or better, a percentage similar to some previous studies. ${ }^{15,20,27}$ The final CDVA was significantly better after CGI than after OGI, most probably due to the absence of corneal scarring with CGI. This finding agrees with a hospital-based report from Eastern China ${ }^{21}$ and another report from Canada. ${ }^{14}$ Eyes with IOLs in the bag had better visual outcome than those with IOLs in the sulcus, as reported by a previous study. $^{28}$ This can be attributed to the greater liability of IOLs in the sulcus for malposition including decentration and tilt compared to IOLs in the bag, a finding described in a previous study. ${ }^{29}$

Amblyopia is a known complication of pediatric traumatic cataract, especially at a young age. As most eye injuries $(85.3 \%)$ in this study occurred after the age of 5 years, the rate of amblyopia (6\%) was relatively lower than that previously reported. ${ }^{12,15}$ Furthermore, cataract surgery was performed within 3 months of eye injury in two-thirds of cases (22 eyes).

This study proved that cataract surgery with IOL implantation has led to an improvement of visual acuity when done early enough to avoid stimulus deprivation amblyopia, in agreement with other reports that described good visual outcomes with early intervention. ${ }^{30,31}$ On the other hand, delayed intervention in one eye in our series led to irreversible deep amblyopia, as supported by previous reports. $^{27}$

Pediatric traumatic cataract surgery is associated with a high risk of PCO. ${ }^{32}$ In our study, significant visual axis obscuration due to PCO was developed in $31.2 \%(5 / 16)$ of eyes with an intact posterior capsule, which is less than that reported by one older study $(41 \%){ }^{20}$ The improvement of the surgical technique, visualization, and instrumentation with meticulous removal of lens matter can explain the reduced incidence of this complication. None of the eyes with posterior capsulotomy and anterior vitrectomy developed PCO, indicating the importance of this step in reducing the incidence of PCO, in agreement with a report of Jinagal et al. ${ }^{15}$

The postoperative inflammation is expected to be more severe in pediatric eyes. Significant anterior uveitis was observed in two eyes $(5.9 \%)$, an incidence comparable to previous studies. ${ }^{14,20}$ Topical steroids and cycloplegics were routinely prescribed postoperatively and tapered according to the inflammatory response, and systemic steroids were added in resistant cases. One study recommended intracameral triamcinolone injection at the time of pediatric traumatic cataract surgery for the prevention of significant postoperative uveitis. ${ }^{33}$ We recommend close follow-up of high-risk patients with excessive intraoperative manipulation for early control of the postoperative inflammation.

The main limitations of our study include its retrospective nature, a small number of cases, and a short follow-up period. However, this is the first study to report the epidemiology and outcome of pediatric traumatic cataracts in Upper Egypt.

\section{Conclusion}

Traumatic cataract is a common morbidity encountered in pediatric ocular injuries. Prompt management is associated with favorable visual outcome in eyes without associated posterior segment injuries or amblyopia. Eyes with either OGI or CGI benefit from surgery. The type and place of the implanted IOLs depend on the degree of available capsular 
support, which influences the final visual outcome. Aggressive treatment of postoperative inflammation and early treatment of visual axis obscuration and amblyopia is important to achieve satisfactory results in those vulnerable eyes.

\section{Ethics Statement}

"The committee of Medical Ethics" of the faculty of medicine, Assiut University has reviewed and approved the study proposal, and given the agreement on conducting the research under the number $17,300,490$.

\section{Disclosure}

The authors declared no potential conflicts of interest with respect to the research, authorship, and/or publication of this article.

\section{References}

1. Aghadoost D. Ocular trauma: an overview. Arch Trauma Res. 2014;3: e21639. doi:10.5812/atr.21639

2. Puodžiuvienė E, Jokūbauskienė G, Vieversytė M, et al. A five-year retrospective study of the epidemiological characteristics and visual outcomes of pediatric ocular trauma. BMC Ophthalmol. 2018;18 (1):10. doi:10.1186/s12886-018-0676-7

3. Négrel AD, Thylefors B. The global impact of eye injuries. Ophthalmic Epidemiol. 1998;5:143-169. doi:10.1076/ opep.5.3.143.8364

4. MacEwen CJ, Baines PS, Desai P. Eye injuries in children: the current picture. Br J Ophthalmol. 1999;83(8):933-936. doi:10.1136/ bjo.83.8.933

5. Kaur A, Agrawal A. Paediatric ocular trauma. Curr Sci. 2005;89:43-46.

6. Eckstein M, Vijayalakshmi P, Killedar M, et al. Aetiology of childhood cataract in south India. Br J Ophthalmol. 1996;80(7):628-632. doi:10.1136/bjo.80.7.628

7. Tomkins O, Ben-Zion I, Moore DB, et al. Outcomes of pediatric cataract surgery at a tertiary care center in rural southern Ethiopia. Arch Ophthalmol. 2011;129:1293-1297. doi:10.1001/archophthalmol.20 11.268

8. Johar SR, Savalia NK, Vasavada AR, et al. Epidemiology based etiological study of pediatric cataract in western India. Indian J Med Sci. 2004;58(3):115-121.

9. Gaafar WM. Epidemiology of pediatric cataract in Dakahlia: Uni-center study. Al-Azhar Assiut Med J. 2015;13:186-188.

10. Olatunbosun KM, Temitayo AO, Joseph R-SAI-S, et al. Profile of pediatric cataract seen at Lagos University Teaching Hospital, Nigeria. Pak J Ophthalmol. 2018;34:52-60.

11. El-Sebaity DM, Soliman W, Soliman AMA, et al. Pediatric eye injuries in upper Egypt. Clin Ophthalmol. 2011;5:1417-1423. doi:10.2147/OPTH.S24679

12. Reddy AK, Ray R, Yen KG. Surgical intervention for traumatic cataracts in children: epidemiology, complications, and outcomes. J AAPOS. 2009;13(2):170-174. doi:10.1016/j.jaapos.2008.10.015

13. Gogate P, Sahasrabudhe M, Shah M, et al. Causes, epidemiology, and long-term outcome of traumatic cataracts in children in rural India. Indian J Ophthalmol. 2012;60:481-486. doi:10.4103/0301-4738.100557

14. Yardley A-M, Ali A, Najm-Tehrani N, et al. Refractive and visual outcomes after surgery for pediatric traumatic cataract. J Cataract Refract Surg. 2018;44(1):85-90. doi:10.1016/j.jcrs.2017.09.033
15. Jinagal J, Gupta G, Gupta PC, et al. Visual outcomes of pediatric traumatic cataracts. Eur $J$ Ophthalmol. 2019;29(1):23-27. doi:10.1177/1120672118757657

16. Holladay JT. Proper method for calculating average visual acuity. J Refract Surg. 1997;13(4):388-391.

17. Kuhn F, Morris R, Witherspoon CD. Birmingham Eye Trauma Terminology (BETT): terminology and classification of mechanical eye injuries. Ophthalmol Clin North Am. 2002;15(2):139-143. doi:10.1016/S0896-1549(02)00004-4

18. Pieramici DJ, Sternberg PJ, Aaberg S, et al. A system for classifying mechanical injuries of the eye (globe). Am J Ophthalmol. 1997;123:820-831. doi:10.1016/S0002-9394(14)71132-8

19. Pandey SK, Wilson ME, Trivedi RH, et al. Pediatric cataract surgery and intraocular lens implantation: current techniques, complications, and management. Int Ophthalmol Clin. 2001;41(3):175-196. doi:10.1097/00004397-200107000-00013

20. Krishnamachary M, Rathi V, Gupta S. Management of traumatic cataract in children. J Cataract Refract Surg. 1997;23(Supplement 1):681-687. doi:10.1016/S0886-3350(97)80054-5

21. Xu YN, Huang YS, Xie LX. Pediatric traumatic cataract and surgery outcomes in eastern China: a hospital-based study. Int J Ophthalmol. 2013;6:160-164. doi:10.3980/j.issn.2222-3959.2013.02.10

22. Du Y, He W, Sun X, et al. Traumatic cataract in children in Eastern China: Shanghai Pediatric Cataract Study. Sci Rep. 2018;8(1):2588. doi:10.1038/s41598-018-20982-1

23. Burgos-Elías VY, Marroquín-Sarti MJ, Zimmermann-Paiz MA, et al. Traumatic cataract surgery in pediatric patients. Experience in a site. Arch Argent Pediatr. 2018;116(3):216-219. doi:10.5546/aap.2018. eng. 216

24. Shah MA, Shah SM, Applewar A, et al. Ocular trauma score as a predictor of final visual outcomes in traumatic cataract cases in pediatric patients. J Cataract Refract Surg. 2012;38(6):959-965. doi:10.1016/j.jcrs.2011.12.032

25. Adlina AR, Chong YJ, Shatriah I. Clinical profile and visual outcome of traumatic paediatric cataract in suburban Malaysia: a ten-year experience. Singapore Med J. 2014;55(05):253-256. doi:10.11622/ smedj.2014067

26. Zimmermann A, Magalhães IH, Tanaka HA, et al. Pediatric traumatic cataract review: origin of the trauma. Rev Bras Oftalmol. 2019;78 (2):103-106. doi:10.5935/0034-7280.20180105

27. Gradin D, Yorston D. Intraocular lens implantation for traumatic cataract in children in East Africa. $J$ Cataract Refract Surg. 2001;27(12):2017-2025. doi:10.1016/S0886-3350(01)00823-9

28. Khokhar S, Gupta S, Yogi R, et al. Epidemiology and intermediate-term outcomes of open- and closed-globe injuries in traumatic childhood cataract. Eur $J$ Ophthalmol. 2014;24 (1):124-130. doi:10.5301/ejo.5000342

29. Zhao YE, Gong XH, Zhu XN, et al. Long-term outcomes of ciliary sulcus versus capsular bag fixation of intraocular lenses in children: an ultrasound biomicroscopy study. PLoS One. 2017;12(3):e0172979. doi:10.1371/journal.pone.0172979

30. Bhandari A, Jorvekar S, Singh P, et al. Outcome after cataract surgery in patients with traumatic cataract. Delta J Ophthalmol. 2016;17 (2):56-58. doi:10.4103/1110-9173.189074

31. Bekibele CO, Fasina O. Visual outcome of traumatic cataract surgery in Ibadan, Nigeria. Niger J Clin Pract. 2008;11:372-375.

32. Trivedi RH, Wilson ME. Posterior capsule opacification in pediatric eyes with and without traumatic cataract. J Cataract Refract Surg. 2015;41:1461-1464. doi:10.1016/j.jcrs.2014.10.034

33. Mohamed TA, Soliman W, Fathalla AM. Effect of intracameral triamcinolone acetonide on postoperative intraocular inflammation in pediatric traumatic cataract. Eur $J$ Ophthalmol. 2016;26 (2):114-117. doi:10.5301/ejo.5000648 


\section{Publish your work in this journal}

Clinical Ophthalmology is an international, peer-reviewed journal covering all subspecialties within ophthalmology. Key topics include: Optometry; Visual science; Pharmacology and drug therapy in eye diseases; Basic Sciences; Primary and Secondary eye care; Patient Safety and Quality of Care Improvements. This journal is indexed on PubMed
Central and CAS, and is the official journal of The Society of Clinical Ophthalmology (SCO). The manuscript management system is completely online and includes a very quick and fair peer-review system, which is all easy to use. Visit http://www.dovepress.com/ testimonials.php to read real quotes from published authors.

Submit your manuscript here: https://www.dovepress.com/clinical-ophthalmology-journal 